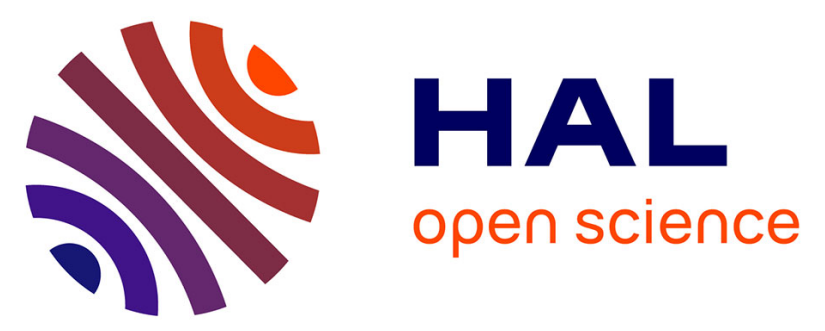

\title{
Antibacterial and antifungal activity of defensins from the Australian paralysis tick, Ixodes holocyclus
}

Alejandro Cabezas-Cruz, Miray Tonk, Mark R. Bleackley, James J. Valdes, Roberto A. Barrero, Angélica Hernández-Jarguín, Sara Moutailler, Andreas Vilcinskas, Florence Richard-Forget, Marilyn A. Anderson, et al.

\section{To cite this version:}

Alejandro Cabezas-Cruz, Miray Tonk, Mark R. Bleackley, James J. Valdes, Roberto A. Barrero, et al.. Antibacterial and antifungal activity of defensins from the Australian paralysis tick, Ixodes holocyclus. Ticks and Tick-borne Diseases, 2019, 10 (6), pp.1-30. 10.1016/j.ttbdis.2019.101269 . hal-02624114

\section{HAL Id: hal-02624114 https://hal.inrae.fr/hal-02624114}

Submitted on 28 Sep 2020

HAL is a multi-disciplinary open access archive for the deposit and dissemination of scientific research documents, whether they are published or not. The documents may come from teaching and research institutions in France or abroad, or from public or private research centers.
L'archive ouverte pluridisciplinaire HAL, est destinée au dépôt et à la diffusion de documents scientifiques de niveau recherche, publiés ou non, émanant des établissements d'enseignement et de recherche français ou étrangers, des laboratoires publics ou privés. 
Original article

\title{
Antibacterial and antifungal activity of defensins from the Australian paralysis tick, Ixodes holocyclus
}

\author{
Alejandro Cabezas-Cruz ${ }^{\mathrm{a}, *, 1}$, Miray Tonk ${ }^{\mathrm{b}, \mathrm{c}, 1}$, Mark R Bleackley ${ }^{\mathrm{d}}$, James J Valdés ${ }^{\mathrm{e}, \mathrm{f}, \mathrm{g}}$, \\ Roberto A Barrero $^{\mathrm{h}}$, Angélica Hernández-Jarguín ${ }^{\mathrm{i}}$, Sara Moutailler ${ }^{\mathrm{a}}$, Andreas Vilcinskas ${ }^{\mathrm{b}, \mathrm{c}, \mathrm{j}}$, \\ Florence Richard-Forget ${ }^{k}$, Marilyn A Anderson ${ }^{c}$, Manuel Rodriguez-Valle, ${ }^{1, *}$ \\ ${ }^{a}$ UMR BIPAR, INRA, ANSES, Ecole Nationale Vétérinaire d'Alfort, Université Paris-Est, Maisons-Alfort, 94700, France \\ ${ }^{\mathrm{b}}$ Institute for Insect Biotechnology, Justus Liebig University of Giessen, Heinrich-Buff-Ring 26-32, 35392, Giessen, Germany \\ ${ }^{\mathrm{c}}$ LOEWE Centre for Translational Biodiversity Genomics (LOEWE-TBG), Senckenberganlage 25, 60325, Frankfurt, Germany \\ ${ }^{\mathrm{d}}$ Department of Biochemistry and Genetics, La Trobe Institute for Molecular science, La Trobe University, Melbourne, Victoria 3086, Australia \\ ${ }^{\mathrm{e}}$ Faculty of Science, University of South Bohemia, 37005, České Budějovice, Czech Republic \\ ${ }_{\mathrm{f}}^{\mathrm{f}}$ Institute of Parasitology, Biology Center, Czech Academy of Sciences, 37005, České Budějovice, Czech Republic \\ ${ }^{\mathrm{g}}$ Department of Virology, Veterinary Research Institute, Brno, Czech Republic \\ ${ }^{\mathrm{h}}$ Centre for Comparative Genomics, Murdoch University, Perth, WA 6150, Australia \\ ${ }^{\mathrm{i}}$ SaBio, Instituto de Investigación de Recursos Cinegéticos, IREC-CSIC-UCLM-JCCM, Ciudad Real, Spain \\ ${ }^{\mathrm{j}}$ Fraunhofer Institute for Molecular Biology and Applied Ecology, Department of Bioresources, Winchester Strasse 2, 35394, Giessen, Germany \\ ${ }^{\mathrm{k}}$ INRA, UR1264 MycSA, 71 Avenue Edouard Bourlaux, 33882, Villenave d'Ornon cedex, France \\ ${ }^{1}$ Queensland Alliance for Agriculture \& Food Innovation, The University of Queensland, St. Lucia, Queensland 4072, Australia
}

\section{A R T I C L E I N F O}

\section{Keywords:}

Ticks

Defensins

Antibacterial activity

Antifungal activity

Ixodes holocyclus

\begin{abstract}
A B S T R A C T
Tick innate immunity involves humoral and cellular responses. Among the humoral effector molecules in ticks are the defensins which are a family of small peptides with a conserved $\gamma$-core motif that is crucial for their antimicrobial activity. Defensin families have been identified in several hard and soft tick species. However, little is known about the presence and antimicrobial activity of defensins from the Australian paralysis tick Ixodes holocyclus. In this study the $I$. holocyclus transcriptome was searched for the presence of defensins. Unique and non-redundant defensin sequences were identified and designated as holosins $1-5$. The antimicrobial activity of holosins 2 and 3 and of the predicted $\gamma$-cores of holosins 1-4 (HoloTickCores 1-4), was assessed using Gramnegative and Gram-positive bacteria as well as the fungus Fusarium graminearum and the yeast Candida albicans. All holosins had molecular features that are conserved in other tick defensins. Furthermore holosins 2 and 3 were very active against the Gram-positive bacteria Staphylococcus aureus and Listeria grayi. Holosins 2 and 3 were also active against $F$. graminearum and $C$. albicans and $5 \mu \mathrm{M}$ of peptide abrogate the growth of these microorganisms. The activity of the synthetic $\gamma$-cores was lower than that of the mature defensins apart from HoloTickCore 2 which had activity comparable to mature holosin 2 against the Gram-negative bacterium Escherichia coli. This study reveals the presence of a multigene defensin family in I. holocyclus with wide antimicrobial activity.
\end{abstract}

\section{Introduction}

Pathogen invasion in tick tissues triggers a complex system of defenses mediated by different molecules of the tick's innate immune system (Kopáček et al., 2010; Hajdusek et al., 2013). The synthesis and release of antimicrobial peptides (AMPs) is an important feature of this immune response and defensins are the most studied family of AMPs. Defensins are ubiquitous and multipotent components of the innate immune defense found in diverse organisms including mammals, amphibians, molluscs, nematodes, arthropods, insects and plants (Zhang and Gallo, 2016; Shafee et al., 2017). These peptides vary in size, amino acid composition and structure. However, they all share an antiparallel $\beta$-sheet connected to an $\alpha$-helix by two to three conserved disulfide bonds forming the cysteine-stabilized $\alpha \beta$ motif (CS- $\alpha \beta)$ that is present in all members of this peptide family. In tick defensins this motif includes six cysteine residues which establish disulfide bonds in the

\footnotetext{
* Corresponding authors.

E-mail addresses: cabezasalejandrocruz@gmail.com (A. Cabezas-Cruz), m.rodriguezvalle@uq.edu.au (M. Rodriguez-Valle).

${ }^{1}$ Equal contribution.
} 
conserved combinations Cys1-Cys4, Cys2-Cys5, and Cys3-Cys6 (Chrudimská et al., 2011; Yamaguchi and Ouchi, 2012). Other defensins were suggested to have only two disulfide bonds (Shafee et al., 2017). Alignments of prototypes of all major classes of disulfide-containing antimicrobial peptides, including distinct conformation groups such as defensin, CS- $\alpha \beta$, ranabox, and $\beta$-hairpin revealed a core motif that was absolutely conserved across all classes of disulfide-stabilized antimicrobial peptides. This motif was termed the $\gamma$-core and, in some cases, the $\gamma$-core alone was sufficient for antimicrobial activity (e.g., protegrins, tachyplesins, RTD-1) (Yount and Yeaman, 2004). The synthetic $\gamma$-core motif of scapularisin-20, a defensin from Ixodes scapularis, exhibits a wide-spectrum of antimicrobial activity at micromolar concentrations (Wang and Zhu, 2011). Likewise, synthetic $\gamma$-cores of other defensins from Ixodes ricinus (i.e. DefMT3, DefMT6, and DefMT7) showed strong activity against the phytopathogenic fungi Fusarium culmorum and Fusarium graminearum (Tonk et al., 2015a).

The defensins are predominantly cationic but several anionic peptides have also been described (Ren et al., 2004; Tonk et al., 2014a). Information related to the structural requirements for the antimicrobial activity of the defensins is abundant. Yet their mode of action is not completely understood. Data obtained in different studies indicate two general types of mechanism of action, through peptide-lipid interaction and receptor-mediated recognition processes (Bulet et al., 1999; Wimley, 2010; Bechinger and Gorr, 2017). However, given the high sequence diversity in defensins, both within and between organisms, their specificity and mechanisms of antimicrobial activity are often more complex (Parisi et al., 2018).

AMPs are produced in the tick midgut cells following blood-feeding and invasion by pathogens (Taylor, 2006; Kopáček et al., 2010) such as Borrelia burgdorferi sensu lato (Ceraul et al., 2003) or Anaplasma phagocytophilum (Liu et al., 2012). The antimicrobial activity of various tick defensins has been widely characterized (Kopáček et al., 2010; Wang and Zhu, 2011; Tonk et al., 2014a, b; Sun et al., 2017) using both in vitro and in vivo assays against bacteria, viruses and fungal pathogens (Wang and Zhu, 2011; Tonk et al., 2014a; Sun et al., 2017; Couto et al., 2018). For example, Scapularisin and Scasin from I. scapularis have bactericidal activity against Gram-negative and Gram-positive bacteria (Wang and Zhu, 2011; Tonk et al., 2014a). Similarly, defensins of Haemaphysalis longicornis, HIDFS1 and HIDFS2, have bactericidal activity against Gram-positive and Gram-negative bacteria. in vivo studies with both Haemaphysalis longicornis defensins showed protection against antibiotic-resistant bacteria (Sun et al., 2017). Tick defensins are also active against Plasmodium spp. in in vitro and in vivo models of pathogen infection (Cabezas-Cruz et al., 2016; Couto et al., 2018). Defensins have also been identified and characterized from other tick species including Amblyomma americanum (Todd et al., 2007); Dermacentor silvarum (Wang et al., 2015); Ixodes ricinus (Tonk et al., 2014b) and Rhipicephalus microplus (Fogaça et al., 2004).

In this study we have characterized the defensins from the Australian paralysis tick, Ixodes holocyclus which is a vector of human and animal pathogens such as Rickettsia australis (Queensland tick typhus) and Coxiella burnetii (Q fever) (Graves and Stenos, 2017). Recently an iflavirus has also been identified by next-generation sequencing in this Ixodes sp. (O'Brien et al., 2018). We used a cDNA library
(Rodriguez-Valle et al., 2018) to identify the I. holocyclus defensins and named them as holosins 1 to 5 . Synthetic holosins had different levels of activity against the bacteria Staphylococcus aureus, Staphylococcus epidermidis, Listeria grayi, Escherichia coli and Pseudomonas aeruginosa as well as the plant pathogen fungus Fusarium graminearum and Candida albicans.

\section{Materials and methods}

\subsection{Ixodes holocyclus defensins: Identification and prediction of $\gamma$-core sequences}

Data from the I. holocyclus database (Rodriguez-Valle et al., 2018) were used for the bioinformatics analysis to identify the defensin sequences used in this study. Briefly, fully engorged adult female $I$. holocyclus ticks collected from different locations along the eastern Australian coast were dissected. The salivary glands and viscera were pooled and used for mRNA extraction and preparation of the cDNA libraries that were used in next generation sequencing using Illumina HiSeq 100 bp paired-end read technologies (Rodriguez-Valle et al., 2018). The sequences were analyses using the Basic Local Alignment Search Tool (BLAST) (Altschul et al., 1990) against the String v7 database (Von Mering et al., 2006) and the Unicellular (COG) and Eukaryotic (KOG) Clusters of Orthologous Groups (Tatusov et al., 2003). The NCBI conserved domain database (CDD) (Marchler-Bauer et al., 2010) was screened using RPSBLAST (Goonesekere and Lee, 2008). The selected defensin sequences were then clustered using Markov Cluster Algorithm (MCL) (Enright et al., 2002). I. holocyclus mature defensin sequences were aligned with $\gamma$-cores previously identified in I. ricinus (Tonk et al., 2015a) and I. scapularis (Tonk et al., 2014a) ticks. Ixodes holocyclus mature defensins and $\gamma$-cores were synthesized and their antimicrobial activity was tested.

\subsection{Peptide synthesis, purification and folding}

Synthesis of selected holosins and $\gamma$-cores (Table 1) was commissioned to Pepmic (Suzhou, China) that uses solid-phase peptide synthesis (SPPS) technology to obtain highly-pure peptides (Cabezas-Cruz et al., 2016). Briefly, peptide synthesis was performed using 2-Chlorotrityl chloride resin as the solid support, using the labile base 9-fluorenyl-methyloxy-carbonyl (Fmoc) as protecting group. All the peptide sequences were synthesized according to the principles of SPPS. High Performance Liquid Chromatography (HPLC) grade Fmoc chloride (Fmoc-Cl) protected amino acid-based peptide chemistry was used with standard peptide chemistry coupling protocols. Peptides were purified by reversed phase HPLC and then the mature peptides of holosin 2 and 3 were oxidized using a folding buffer containing $1 \mathrm{M}$ urea, $100 \mathrm{mM}$ Tris $-\mathrm{HCl}(\mathrm{pH} 8.0), 1.5 \mathrm{mM}$ oxidized glutathione, $0.75 \mathrm{mM}$ reduced glutathione and $10 \mathrm{mM}$ methionine. The $\gamma$-cores were used as linear peptides. Complete oxidation of mature peptides was confirmed by Ellman's reagent reaction, and sulfide bond formation was characterized by electrospray mass spectroscopy (ESI-MS) on a mass spectrometer LCMS-2020 (Shimadzu, Kyoto, Kyoto Prefecture, Japan). Sequence composition was verified by ESI-MS using the mass

Table 1

Amino acid sequences of the synthetic holosins and $\gamma$-cores tested in the antimicrobial assays.

\begin{tabular}{lll}
\hline Holosins & Accession numbers & Amino acid sequences of mature holosins* \\
\hline Holosin 1 & MK651041 & GFGCPFNQGACHSHCRSIGRRGGYCAGIIKQTCTCYKS \\
Holosin 2 & MK651042 & GFGCPLNQRACHRHCRSIGRRGGFCAGLIKQTCTCYRK \\
Holosin 3 & MK651043 \\
Holosin 4 & MK651044 & GFGCPNEWRCNAHCKRNRFRGGYCDSWFRRRCHCYG** \\
Holosin 5 & MK651045 & GFGCPFNQGACHNHCRSIGRRGGYCAGFFKQTCTCYHR \\
\end{tabular}

*Underlined are the $\gamma$-cores predicted in this study. Underlined and bold are the $\gamma$-cores selected for synthesis and functional studies. The holosins selected for synthesis and functional studies are shown (**). 
spectrometer LCMS-2020.

\subsection{Phylogenetic analysis}

Tick defensins were aligned using MAFFT (Katoh and Standley, 2013). The alignment was used to infer a maximum likelihood (Wimley) phylogenetic tree. The best-fit model of sequence evolution was selected based on the Corrected Akaike Information Criterion (AICc) and the Bayesian Information Criterion (BIC) as implemented in MEGA 6 (Tamura et al., 2013). Accordingly, the WAG (Whelan and Goldman, 2001) substitution model, which had the lowest values of AICc and BIC, was chosen for subsequent phylogenetic analyses. The ML method implemented in MEGA 6 (Tamura et al., 2013), was used to obtain the best tree topology. All sites of the alignments were used in the tree reconstruction. The proportion of Gamma distributed sites was estimated in MEGA 6 (Tamura et al., 2013). Reliability for internal branches was assessed using the bootstrapping method (1000 bootstrap replicates) implemented in MEGA 6 (Tamura et al., 2013). Graphical representation and editing of the phylogenetic tree was performed with MEGA 6 (Tamura et al., 2013).

\subsection{Tertiary structure prediction and thermodynamics}

The tertiary models of the mature peptides were produced by the ITASSER server (Zhang, 2008). The predicted models were then optimized by minimization and the hydrogen-bond network improved using the Schrodinger's Maestro Protein Preparation Wizard (Sastry et al., 2013). The mature peptides were aligned using MAFFT (Katoh and Standley, 2013) and the sequence conservation was produced using WebLogo (Crooks et al., 2004). Thermodynamics were analysed using the Metropolis Monte Carlo-based Protein Energy Landscape Exploration server (PELE) that is accessible at pele.bsc.es and has been explained elsewhere (Borrelli et al., 2005; Madadkar-Sobhani and Guallar, 2013). Briefly, PELE performs three steps in its algorithm: (1) protein and ligand local perturbation, (2) amino acid side chain sampling, and (3) a global minimization of the system. The steps are repeated for a number of iterations $(10,000)$ computed for $24 \mathrm{~h}$ using the protein motion ready-made script and a single cpu. The result is a series of frames that depict protein dynamics. Enthalpy values $(\mathrm{kcal} / \mathrm{mol})$ are also recorded during the simulations. To calculate enthalpy, the PELE software uses a force field known as the optimized potentials for liquid simulations (OPLS-2005) (Jorgensen et al., 1996). The Metropolis Monte Carlo-based method accepts iteration if the enthalpy is equal to or less than the initial value but is rejected if the enthalpy is greater than the initial value. Further analyses on the molecular simulations were performed using the Visual Molecular Dynamics software (VMD) (Humphrey et al., 1996). A threshold of $0.25 \AA$ every 100 frames for 20 clusters was set for the VMD cluster analysis on the $\alpha$-carbon backbone of the defensin $\gamma$-cores. Averages and $( \pm)$ standard deviations were used to clearly depict the thermodynamics graphically.

\subsection{Antibacterial assays}

Synthetic peptides were used in the antibacterial test at concentrations ranging between 8 and $250 \mu \mathrm{M}$. When a significant decrease in bacterial growth was detected at $8 \mu \mathrm{M}$ compared with the nontreated control, lower concentrations of peptides were used ranging from 0.015 to $8 \mu \mathrm{M}$. Holosins 1,2 and $\gamma$-cores HoloTickCore 1-4 were tested against Gram-negative (i.e. E. coli strain D31 and P. aeruginosa strain DSM 50,071) and Gram-positive (i.e. S. aureus strain DSM 2569, S. epidermidis strain DSM 3269 and L. grayi) bacteria. The assay was performed as previously described (Tonk et al., 2014b). Briefly, the assays were carried out in 384-well plates (Griener Bio One, Frickenhausen, Germany) using Brain Heart Infusion Broth (BHIB) medium for L. grayi or Tryptic Soy Broth (TSB; Roth, Karlsruhe, Germany) for the other bacteria. Cultures in the mid-logarithmic phase were used for growth inhibition assays. The initial optical density (OD), measured at a wavelength of $600 \mathrm{~nm}\left(\mathrm{OD}_{600}\right)$, for $L$. grayi was set to 0.01 and for the rest of the bacteria to 0.001 . Changes in $\mathrm{OD}_{600}$ values were monitored every $20 \mathrm{~min}$ for $24 \mathrm{~h}$ using an Eon Microplate Spectrophotometer (BioTek Instruments, Winooski, VT, USA). Two biological replicates were used for each condition. Controls comprising defensin-free control media and non-inoculated control media were included.

\subsection{Antifungal assays}

Antifungal assays were performed using microbroth dilution assays as described in (Broekaert et al., 1990). Fusarium graminearum PH-1 was maintained on synthetic nutrient-poor agar $\left(0.1 \% \mathrm{KH}_{2} \mathrm{PO}_{4}, 0.1 \% \mathrm{KNO}_{3}\right.$, $0.1 \% \mathrm{MgSO}_{4} \cdot 7 \mathrm{H}_{2} \mathrm{O}, 0.05 \% \mathrm{KCl}, 0.02 \%$ Glucose, $0.02 \%$ Sucrose, $2 \%$ agar) at $25{ }^{\circ} \mathrm{C}$. Candida albicans was maintained on $1 \%$ yeast extract, $2 \%$ peptone, $2 \%$ dextrose (YPD) agar and overnight cultures were performed in liquid YPD at $30^{\circ} \mathrm{C}$. For antifungal assays $F$. graminearum spores were diluted to $5 \times 10^{4}$ spores $/ \mathrm{mL}$ in half-strength potato dextrose broth ( $1 / 2$ PDB) (Merk, Bayswater, Australia) and C. albicans yeast cells were diluted to an $\mathrm{OD}_{600}$ of 0.0002 in $1 / 2$ PDB. Prepared fungi $(90 \mu \mathrm{L})$ were added to a twofold dilution series of peptide between 0.31 and $10 \mu \mathrm{M}$ prepared in water as well as a no-peptide control $(10 \mu \mathrm{L})$. The OD at $595 \mathrm{~nm}$ was measured after $48 \mathrm{~h}$ of incubation at $25^{\circ} \mathrm{C}$ for $F$. graminearum or $24 \mathrm{~h}$ of incubation at $30^{\circ} \mathrm{C}$ for C. albicans. The $\mathrm{OD}_{595}$ of a well with no fungal material and only medium was subtracted from all OD values to correct for background absorbance of the culture medium.

\subsection{Statistical analysis}

All presented values are mean \pm standard deviation including two biological replicates. Since the data were non-normally distributed (Shapiro-Wilk normality test), the Kruskal-Wallis one-way analysis was used, with sum of ranks comparisons performed using Dunn's multiple comparisons test in the GraphPad 6 Prism program (GraphPad Software Inc.). Differences were considered significant when $p$-value $<0.05$.

\section{Results}

\subsection{Molecular characterisation of holosins 1-5, novel defensins in I. holocyclus}

The coding regions of the five defensins (holosins 1-5) were successfully identified in the cDNA library of $I$. holocyclus ticks (Ong et al., 2018; Rodriguez-Valle et al., 2018). In two of the holosins (holosin 3 and 5), the start codon 'ATG', coding for methionine (M), was not present and therefore there is a high likelihood that these are partial sequences. STOP codons were identified in all defensins. The holosins exhibited the typical molecular properties of CS- $\alpha \beta$ defensins. Using the SignalP 4.1 Server (Petersen et al., 2011), the first 18 and 22 amino acids were predicted as signal peptides of holosins 1 and 4, indicating that these defensins are most likely secreted. In agreement with this, subcellular localization prediction using DeepLoc 1.0 Server (Almagro Armenteros et al., 2017) revealed that all holosins (1-5) have a high likelihood ( $>0.99$ ) to be extracellular and soluble molecules. However, despite having a starting codon, no signal peptide was predicted for holosin 2. The furin cleavage site (RVRR) described by (Krysan et al., 1999) was present in all holosins, as well as the six conserved Cys residues that form the three disulfide bridges (Fig. 1). After theoretical furin cleavage, the peptides were 36 (holosin 3), 38 (holosins 1, 2 and 4) and 39 (holosin 5) amino acids in length (Table 1). In agreement with the above conserved molecular properties, the Conserved Domain Database (CDD) server (Marchler-Bauer et al., 2015) classified holosins 1, 2, 4 and 5 as members of the Defensin-2 family (pfam01097) with $E$ values $<2.29 \mathrm{e}-05$. However, no conserved domain was identified by CDD for holosin 3. The BLAST hits with the lowest $E$-values and highest $\%$ identity were obtained with defensins from the ticks $H$. longicornis, $A$. 


Aam: Amercin (ABI74752)
Hlg: DFS1 (ATN39847)
HIg: DFS2 (ATN39848)
Iho: Holosin1 (MK651041)
Iho: Holosin2 (MK651042)
Iho: Holosin3 (MK651043)
Iho: Holosin4 (MK651044)
Iho: Holosin5 (MK651045)
Iri: Prodefensin (AY335442)
Isc: Prodefensin (EEC03289)
Isc: Prodefensin (EEC17844)
Isc: MT3 (JAA71488)
Isc: Prodefensin (EEC08554)
Isc: Scapularisin (AY660970)
Isc: Scapularisin (EEC08935)
Isc: Scapularisin (EEC08933)
Ipe: Persulcatusin (AB469201)
Isc: AMP (EEC08934)
Isc: AMP (EEC13914)
Isc: Defensin (EEC17916)
Rmi: Defensin (AY233213)

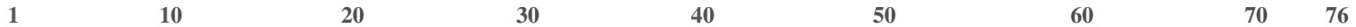
MKVLAVAFIFVLVAGLVSTADEEDK--SQVPLVRVRRG-FGCPFNQYQCHSHCLSIGRR-GGYCGGSFKTTCTCYN MKLLAVVLALVLVIGAVAKG-AVTEEKGEVAHLRVRRWGFGCPFNARRCHRHCRS IRRR-AGYCAGRLRLTCTCVR MRVLVLSLAVILLCGLMAGSATAEEE-SEVAHLRVRRG-FGCPLNQGACHRHCRS IRRR-GGYCSGI IKQTCTCYRN MKVLAIAVLSLLVAGVFTASFHGBHB-SBIAHVRVRRG-FGCPFNQGACHSHCRS IGRR-GGYCAGIIKQTCTCYKS MLVAGVVNASAAEEGD-SGAAHVRVRRG-FGCPLNQRACHRHCRS IGRR-GGFCAGLIKQTCTCYRK PQTGHVRVRRG-FGCP-NEWRCNAHCKRNRFR-GGYCDSWFRRRCHCYG MKVVAVAFIFVLVAGLISASSADDAD-SEGAHVRVRRG-FGCPFNOGACHNHCRSIGRR-GGYCAGFFKOTCTCYHR LVFVLIVGAISTSTAEKSP-SEVAHLRVRRWWFGCPFNQRVCHRHCRSIKRR-AGYCGGPFKRTCTCVVN MKVLAVSLAFLLIAGLISTSLAQNEEGGEKELVRVRRGGYYCPFFQDKCHRHCRSFGRK-AGYCGGFLKKTCICVM MKVLAVSLAFLLIAGLISTSFAQNEEGGEKELVRVRRGGYYCPFFQDKCHRHCLS IGRR-AGYCGGFLKKTCICVMK MKVLAVPLAFLLVVGLISTSLAQNGEGGEKELVRVRRGGYYCPFRQDICHNHCRSFGRK-AGYCGGFLKKTCICVMK MKVLAVSLAFLLIAGLITSSLAENDEGGEKELVRVRRGGYYCPFRODKCHRHCRSFGRK-AGYCGNFLKRTCICVKK MKVLAVSLAFLLIIGLISTSLAENNKEGEKDLVRVRNG-YYCPFQQDKCHLHCIS IGRK-AGYCGNFLKRTCICVMK MRVIAVTLIALLVAGAFMTSSAQEEE-NQVAHVRVRRG-FGCPFDQGACHRHCQSIGRR-GGYCAGFIKQTCTCYHN MRVIAVTLIALLVAGAFMTSSAQEEE-NQVAHVRVRRG-FGCPFDQGACHRHCQSIGRR-GGYCAGFIKQTCTCYHN MKVIAVALIALLVAGAFMTS SAQEEE-DQVAHVRVRRG-FGCPFDQGACHRHCQSIGRR-GGYCAGI IKQTCTCYHN MRVVAVALIALLVAGAFMTSSAOEEE-NOVAHVRVRRG-FGCPFNOGACHRHCRSIGRR-GGYCAGLFKOTCTCYSR MKAVAIALVVMMIAGLISTSCSQEDD-SQVAHVRVRRG-FGCPLNQGACHNHCRSIKRR-GGYCSGIIKQTCTCYRK MKVVGIA----LVVRLFSFSCSQGVH-SQVPHVRVRRA-FGCPFDQGTCHSHCRS IRRR-GERCSGFAKRTCTCYQK MNTSSLFTVALIAFAGFMTIOLVSPY----VIOPFFDIG-FGCPKSALSCSOOCRENNTHSGGYCNGPFNIVCSCY MRGIYICLXFVLXCGLVSGLADVPAE-SEMAHLRVRRG-FGCPFNQGACHRHCRSIRRR-GGYCAGLIKQTCTCYRN

Fig. 1. Alignment of tick defensins. The alignment included Amblyomma americanum (Aam), Ixodes scapularis (Isc), Ixodes ricinus (Iri), Haemaphysalis longicornis (Hlg), Rhipicephalus microplus (Rmi), Ixodes persulcatus (Ipe) and Ixodes holocyclus (Iho) defensins (Holosin). The highly conserved Cys residues are in bold font. UniProt names and GenBank numbers were included to simplify the identification of each peptides.

Table 2

Tick defensins with the highest percent of identify and lowest $E$-values compared with holosins.

\begin{tabular}{lll}
\hline Holosins & Closest relative (accession number) & Identity (\%) \\
\hline Holosin 1/2 & Haemaphysalis longicornis (defensin 2, ABW08118) & $\geq 71.6$ \\
Holosin 4/5 & Ixodes persulcatus (persulcatusin, BAH09304) & $\geq 1 \mathrm{e}-20$ \\
Holosin 3 & Amblyomma americanum (amercin, ABI74752) & $\leq 1 \mathrm{e}-21$ \\
\hline
\end{tabular}

americanum and Ixodes persulcatus (Table 2). To further characterize the evolutionary history of holosins, hard and soft tick defensin sequences were collected from GenBank and a Maximum Likehood phylogenetic tree was reconstructed (Fig. 2). While most Ixodes defensins clustered together, holosins clustered in different clades suggesting high diversity among I. holocyclus defensins. Holosin 3 was the only defensin from hard ticks that clustered with soft tick defensins.

\subsection{Synthesis, purity and folding of holosins}

The sequence and purity (i.e. $\sim 95 \%$ purity) of the synthetized $\gamma$ cores was confirmed by HLPC (Supplementary Fig. S1) and ESI-MS (Supplementary Fig. S2), respectively. The observed molecular weights (MW, in Da) of the purified $\gamma$-cores HoloTickCore 1 (MW: 1518.60), 2 (MW: 1588.05), 3 (MW: 1688.70) and 4 (MW: 1664.85) corresponded with the theoretical MW for each of them (HoloTickCore 1: formula: $\mathrm{C}_{63} \mathrm{H}_{107} \mathrm{~N}_{17} \mathrm{O}_{20} \mathrm{~S}_{3}$, MW: 1518.82; 2: formula: $\mathrm{C}_{66} \mathrm{H}_{114} \mathrm{~N}_{20} \mathrm{O}_{19} \mathrm{~S}_{3}$, mw: 1587.93; 3: formula: $\mathrm{C}_{71} \mathrm{H}_{101} \mathrm{~N}_{25} \mathrm{O}_{18} \mathrm{~S}_{3}$, MW: 1688.92; and 4: formula: $\mathrm{C}_{72} \mathrm{H}_{105} \mathrm{~N}_{21} \mathrm{O}_{19} \mathrm{~S}_{3}$, MW: 1664.94). Mature holosins 2 and 3 were purified and refolded in folding buffer to obtain the peptides in their thermodynamically most stable form. Final purification of folded peptide was achieved by reversed phase HPLC and highly pure peptides (i.e. $~ 95 \%$ purity) were obtained (Supplementary Fig. S1). ESI-MS and Ellman's reagent were used to further characterize the folding status. The MW of holosins 2 and 3 having three -SS --bonds should be approximately 6 less than the MW before the oxidation (considering that the MW of hydrogen, $\mathrm{H}^{+}$, is approximately 1 ), resulting from the loss of $6 \mathrm{H}^{+}$from the six reduced sulfhydryl groups $(-\mathrm{SH})$. This was confirmed using ESI-MS. While the observed MW of linear holosins 2 (Formula: C177H289N65O46S6 and theoretical MW: 4256.05) and 3 (Formula: C187H269N67O47S6 and theoretical MW: 4400.01) were 4256.80 and 4401.00 , the observed MW determined by ESI-MS after the folding protocol were 4249.80 and 4394.10, respectively (Supplementary Fig. S3). Quantitative analysis of -SH revealed that no cysteine residues were available for complexing with the Ellman's reagent, indicating, in combination with the ESI-MS results, that all cysteines were involved in intramolecular disulfide linkages.

\subsection{Structural characterization and thermodynamics of holosins}

There are 181 defensins (as a keyword) that are structurally resolved in the Protein Databank (Berman et al., 2000). The tertiary structures of the I. holocyclus defensins were therefore predicted to further characterize these holosins (Fig. 3a). Similar to vertebrate $\beta$ defensins, the five I. holocyclus holosins are predicted to form a Cysstabilized $\alpha / \beta$-fold (CS- $\alpha \beta$ ) with an amino-terminal $\alpha$-helix that stabilizes the $\beta$-hairpin via three Cys disulfide bridges (I-III; Fig. 3a). The CS$\alpha \beta$-fold comprises of several structural motifs known as the $\alpha$-patch, mapped onto the $\alpha$-helix, and the loops designated by peptide positions at the amine-terminus (n-loop), middle (m-loop) and carboxyl-terminus (c-loop) (Zhu et al., 2012). The main structural features common to the I. holocyclus holosins are the distinct folds at the loop regions, specifically the $\mathrm{n}$ - and c-loop, that are characterized by large conformational differences in the first (I) Cys disulfide bridge (Fig. 3a).

The DALI server (Holm and Laakso, 2016), a structural heuristic search engine that scans the Protein Databank, was used to identify defensins with the CS- $\alpha \beta$-fold that are similar to the predicted I. holocyclus holosins (Fig. 3a). According to the DALI server, the closest structural homolog is the antimicrobial defensin, eurocin, from the mold Eurotium amstelodami (Protein Databank accession: 2LT8) that possesses antimicrobial activity against a variety of Gram-positive human pathogens (Oeemig et al., 2012). Eurocin, however, is not effective against Gram-negative pathogens (Oeemig et al., 2012). Eurocin shares $45 \%-55 \%$ sequence identity with the $I$. holocyclus holosins (Fig. 3b). The six Cys residues that form the three disulfide bridges, the amine-terminus of the n-loop, the $\alpha$-patch His, and the Gly after the mloop are the most conserved (Fig. 3b). Two main indels occur for eurocin and the holosins: firstly, near the junction of the $\alpha$-patch and $\mathrm{m}$ loop (Gly,Gly), and (2) at the c-loop (Tyr,Leu,Gly) (Fig. 3b). As shown from the nuclear magnetic resonance study by Oeemig et al. (2012), the 


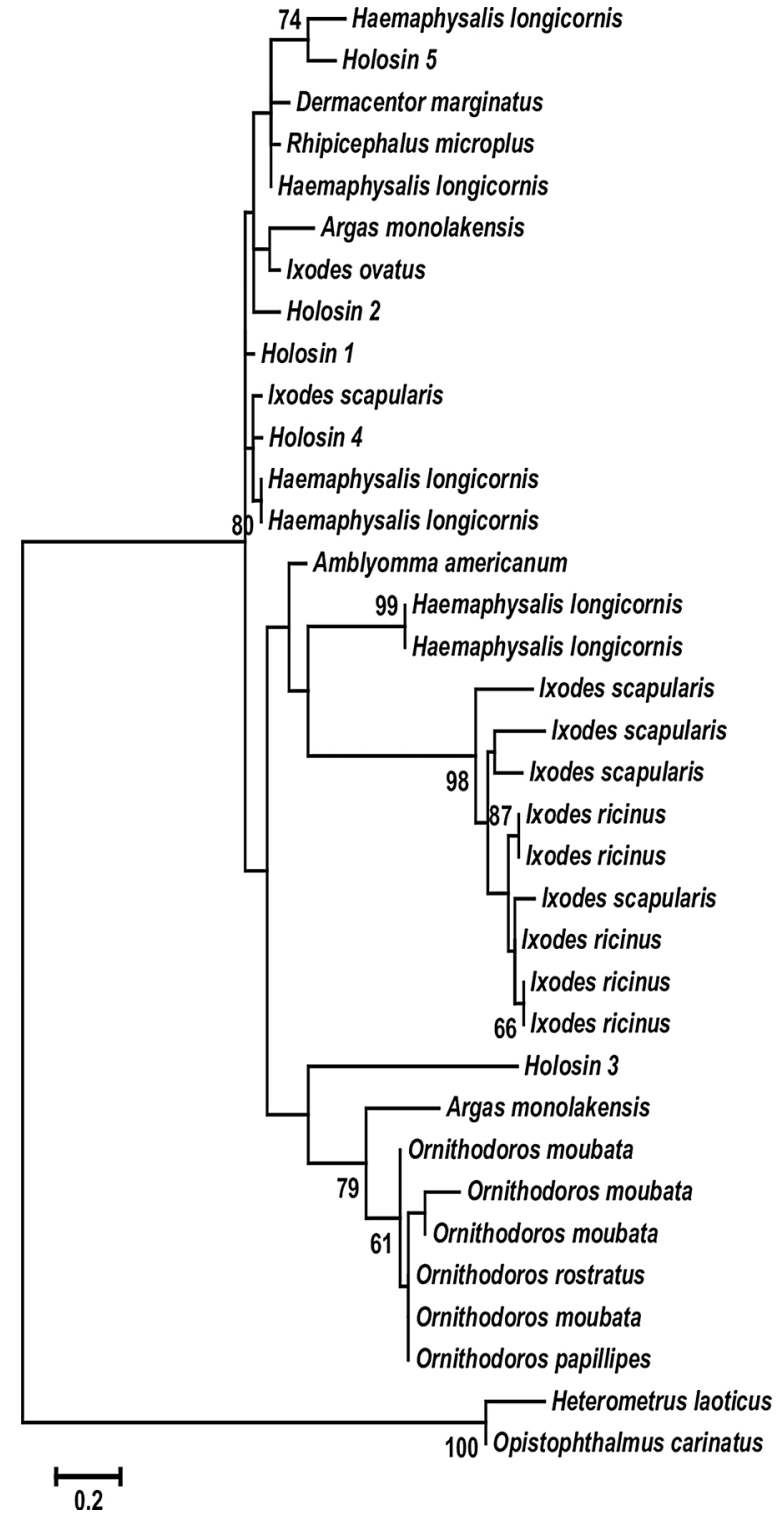

Fig. 2. Phylogenetic tree of tick defensins. The evolutionary history of tick defensins was inferred using the Maximum Likelihood method based on the WAG model. The tree with the highest log likelihood (-947.25) is shown. Initial tree(s) for the heuristic search were obtained automatically by applying Neighbor-Join and BioNJ algorithms to a matrix of pairwise distances estimated using a JTT model, and then selecting the topology with superior log likelihood value. A discrete Gamma distribution was used to model evolutionary rate differences among sites ( 5 categories $(+G$, parameter $=1.7582)$ ). The tree is drawn to scale, with branch lengths measured in the number of substitutions per site. The analysis involved 35 amino acid sequences. All positions containing gaps and missing data were eliminated. There was a total of 40 positions in the final dataset. The percentage of trees (bootstrap values) in which the associated taxa clustered together is shown next to the branches.

c-loop region of eurocin is subject to large conformational changes.

The $\gamma$-core, a main constituent of the antimicrobial activity of $\beta$ defensins (Nigro et al., 2015), harbors the $\mathrm{m}$ - and c-loop portion of the $\beta$-hairpin (Fig. 3b). The indel caused by the additional residues (Tyr, Leu, Gly) at the c-loop, that is within the $\gamma$-core, and large conformational changes may increase steric flexibility and conformational search for substrate targets. Such conformational flexibility has been hypothesized to increase target promiscuity of peptide inhibitors against proteases (Valdes et al., 2013). To investigate the conformational flexibility of the $\gamma$-core, molecular simulations were conducted on eurocin and holosin defensins (see Materials and Methods). The first 3000 frames were deleted from the analysis since all defensins, specifically holosin 1 , reach a steady enthalpy $(\mathrm{kcal} / \mathrm{mol})$ state at this point of the simulations (Fig. 3c), i.e., the last $\approx 000$ frames were then analyzed.

Analyses from the molecular simulations revealed that holosin 2, holosin 3 and holosin 5 have more flexible $\gamma$-cores than the other defensins from this study. This $\gamma$-core flexibility is demonstrated by their respective high root mean square deviations - holosin $2: 0.9 \AA \pm 0.3 \AA$, holosin 3: $0.8 \AA \pm 0.4 \AA$ and holosin 5: $1.1 \AA \pm 0.3 \AA$ (Fig. 3d). Holosin 3 , however, is predicted to be highly exothermic (lower enthalpy values; $-1591 \mathrm{kcal} / \mathrm{mol} \pm 3.3 \mathrm{kcal} / \mathrm{mol}$ ) indicating that it releases more energy (or heat) than the other defensins (Fig. 3d). Fig. 3e shows the possible conformations of the holosin $5 \gamma$-core during the molecular simulations. The main conformational changes, as depicted in the most flexible holosin holosin 5, occur at the c-loop region of the $\gamma$-core (Fig. 3e).

\subsection{Antimicrobial activity of holosins}

Based on the structural analysis, we selected holosins 2 and 3 (for possessing highly flexible $\gamma$-cores) and the $\gamma$-cores HoloTickCore 1, 2, 3 and 4 for synthesis and antimicrobial assays against Gram-negative bacteria (E. coli and P. aeruginosa), Gram-positive bacteria (S. aureus, $S$. epidermidis and $L$. grayi) and fungi ( $F$. graminearum and $C$. albicans). Bacterial growth in liquid medium in the presence and absence of holosins 2 and 3 and $\gamma$-cores HoloTickCore 2 and 3 at six different concentrations 8, 15, 30, 60, 120 and $250 \mu \mathrm{M}$ is displayed in Fig. 4. Holosins 2 and 3 were active against all the bacteria tested, whereas HoloTickCores 2 and 3 were only active against $E$. coli. Likewise, the antibacterial activity of HoloTickCores 1 and 4 was very limited and was only observed at the highest concentration $(250 \mu \mathrm{M})$ used against E. coli (HoloTickCores 1 and 4) and P. aeruginosa (HoloTickCore 1) (Supplementary Fig. S4). In contrast, holosins 2 and 3 at the concentration of $8 \mu \mathrm{M}$ almost abrogated the growth of the Gram-positive bacteria $S$. aureus and L. grayi. At lower concentrations (i.e. $0.015 \mu \mathrm{M}$ ) holosins 2 and 3 decreased the growth of both $S$. aureus and L. grayi more than seven times compared to the controls (Supplementary Fig. S5).

Concerning antifungal activity, $5 \mu \mathrm{M}$ of holosins 2 and 3 almost abrogated the growth of $F$. graminearum and $C$. albicans (Fig. 5). None of the HoloTickCores were active against the fungal or yeast pathogens (Fig. 5 and Supplementary Fig. S4).

\section{Discussion}

The humoral immune response in ticks against invading microorganisms involves the transcriptional activation of defensins (Kopáček et al., 2010; Hajdusek et al., 2013). Multigene defensin families have been reported for several tick species including hard ticks I. scapularis (Wang and Zhu, 2011), I. ricinus (Chrudimská et al., 2011; Tonk et al., 2014b), Rhipicephalus sanguineus sensu lato (Anatriello et al., 2010), $H$. longicornis (Sun et al., 2017) and soft ticks Ornithodoros moubata (Nakajima et al., 2002), Ornithodoros papillipes, Ornithodoros tartakovskyi and Ornithodoros puertoricensis (Chrudimska et al., 2010). In this study we searched a cDNA library (Ong et al., 2018; Rodriguez-Valle et al., 2018) to identify the defensins produced by the Australian paralysis tick, $I$. holocyclus. The analysis led to the identification and annotation of five defensins, named holosins $1-5$. This is fewer than the 45 defensins identified in I. scapularis (Wang and Zhu, 2011), but is comparable to the six defensins produced by I. ricinus (Chrudimská et al., 2011; Tonk et al., 2014b). The holosins reported and annotated here display features present in other tick defensins, namely (i) a signal peptide (detected only in holosins 1 and 4); (ii) a furin cleavage recognition site; (iii) the six conserved Cys residues; (iv) the functional motifs consisting of the n-loop, $\alpha$-patch, m-loop, c-loop and $\gamma$-core; (v) 

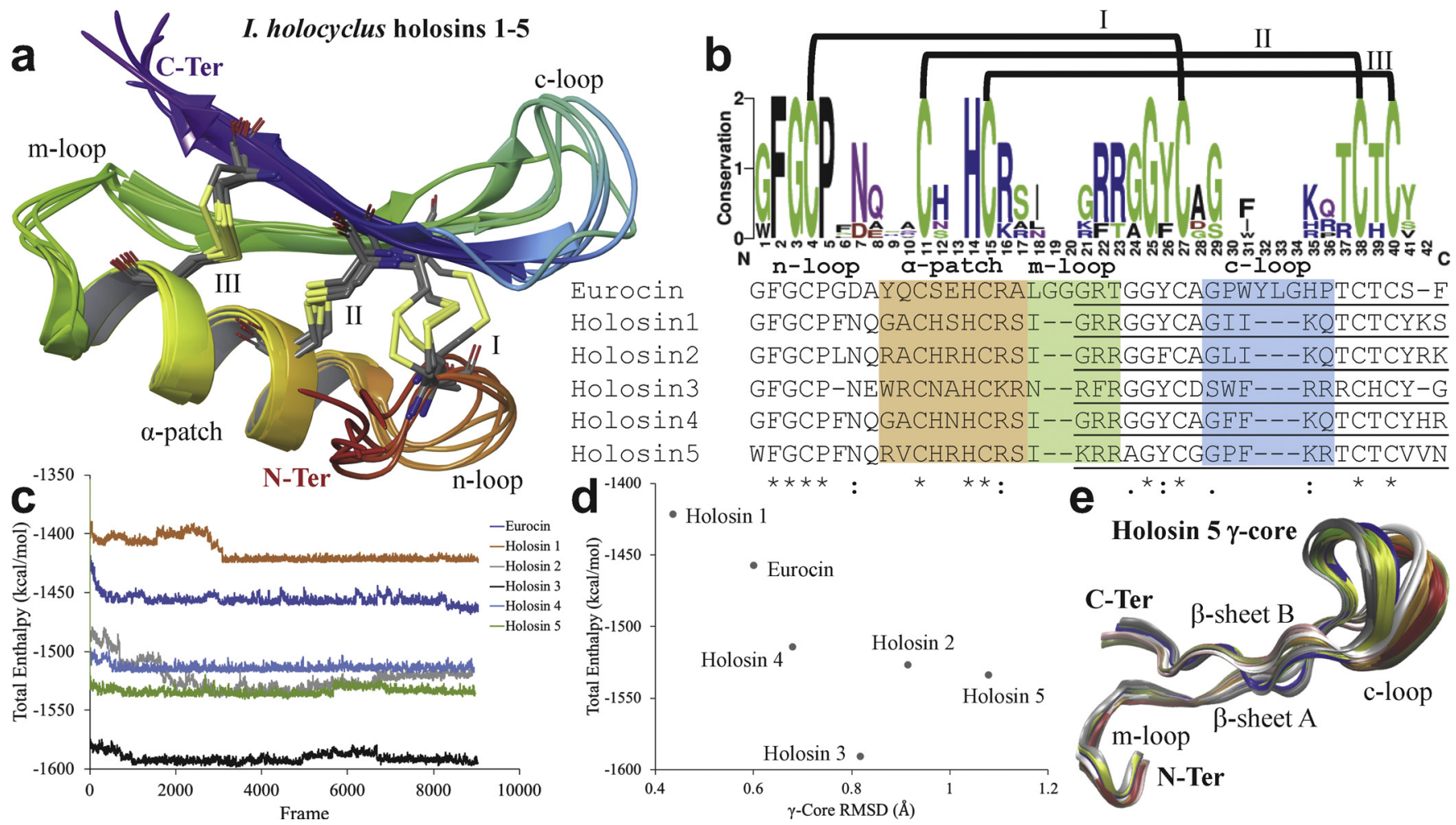

Eurocin Holosin1 Holosin2 Holosin3 Holosin 4 Holosin 5

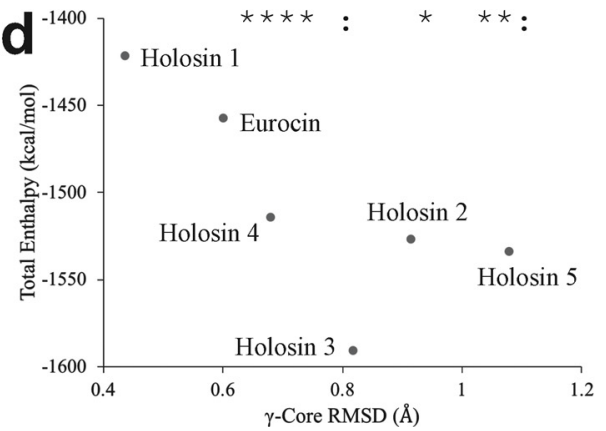

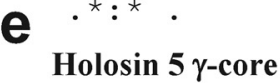

\section{C-Ter}

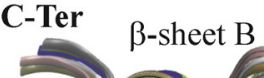

Fig. 3. Tertiary predicted structures and thermodynamics of $I$. holocyclus defensins. The superposed predicted tertiary structures of the holosins are shown (a) from the amino-terminus (N-Ter; red) to the carboxyl-terminus (C-Ter; purple) with the three Cys disulfide bridges as Roman numerals and I-III the loop/patches respectively labeled. The protein sequence weblogo (b) depicts the amino acid ( $x$-axis) conservation ( $0-2 ; y$-axis) between eurocin and the holosins with the three Cys disulfide bridges I-III labeled with brackets. The aligned sequences below show the loops/patches respectively color-labeled to the tertiary structure (a) with the $\gamma$ cores underlined as described by (Nigro et al., 2015). The (c) total enthalpy (kcal/mol; $y$-axis) for each frame ( $x$-axis) during the molecular simulations for each defensin. The average (d) root mean square deviation (RMSD; $x$-axis) of the $\gamma$-core for each defensin (labelled) plotted against its respective enthalpy (kcal/mol; $m$ axis). The top conformations (e) from the cluster analysis (see Materials and Methods) depicting the flexibility of the holosin $5 \gamma$-core with motifs and secondary structures labeled for orientation. (For interpretation of the references to colour in this figure legend, the reader is referred to the web version of this article).

two C-terminal anti-parallel $\beta$-strands; (vi) and an $\alpha$-helix at the $\mathrm{N}$ terminus. The highly dispersed distribution of holosins in the phylogenetic tree revealed high diversity in the amino acid sequences of the $I$. holocyclus defensins. A previous study using ancestral reconstruction of tick defensins led to the hypothesis that amino acid variability and defensin family expansion increased the antimicrobial spectrum of ancestral tick defensins (Cabezas-Cruz et al., 2016). This is supported by the observation that the holosins were active against three major classes of microorganisms including Gram-positive and Gram-negative bacteria and fungi. The antimicrobial spectrum of holosins is comparable to that reported for the I. ricinus defensins DefMT3, DefMT5 and DefMT6 (Tonk et al., 2015a). Notably, while the lowest minimum inhibitory concentration (MIC) of $I$. ricinus defensins against L. grayi was $2 \mu \mathrm{M}$ for DefMT6, the MIC of holosin 3 was less than $0.015 \mu \mathrm{M}$. The high effectivity of holosins 2 and 3 against Gram-positive bacteria (S. aureus and $L$. grayi) compared to the lower activity against Gram-negative bacteria is in agreement with the antimicrobial activity of their closest structural homolog, eurocin. Eurocin possesses antimicrobial activity against a variety of Gram-positive bacteria, but is not is not as effective against Gram-negative bacteria (Oeemig et al., 2012). The antimicrobial activity of defensins is correlated by its ability to compromise the target cytoplasmic membrane that has been shown to kinetically vary among defensins (Nakajima et al., 2003). Additionally, the limited effect of the holosins on Gram-negative bacteria might explain the efficacy of $I$. holocyclus as a vector for R. australis (Queensland tick typhus) and C. burnetii (Graves and Stenos, 2017), both being Gram-negative bacteria.

Similar results were obtained with $H$. longicornis defensins with antimicrobial activity against bacteria and fungi (C. albicans), and against drug-resistant microorganisms (Sun et al., 2017). Also, longicin from $H$. longicornis inhibits the proliferation of Babesia equi merozoites and reduced the parasitemia in animals infected with the zoonotic pathogen Babesia microti (Tsuji et al., 2007). Scapularisin-20 from I. scapularis has a broad range of antimicrobial activity against both Grampositive and Gram-negative bacteria (Wang and Zhu, 2011). Dermacentor silvarum defensins have strong activity against Gram-positive bacteria such as $S$. aureus, Bacillus pumilus, Micrococcus luteus, and Mycobacterium bovis, but less effect on Gram-negative bacteria such as Salmonella typhimurium, P. aeruginosa, and E. coli (Wang et al., 2015). Furthermore, the I. ricinus defensins are active against the apicomplexan parasites Plasmodium falciparum and Plasmodium chabaudi (Cabezas-Cruz et al., 2016; Couto et al., 2018).

In contrast to previous reports of antimicrobial activity of tick $\gamma$ cores from I. ricinus and I. scapularis defensins (Wang and Zhu, 2011; Tonk et al., 2015a), the HoloTickCores showed no or very low efficacy compared to the mature holosins. Similarly, in plant defensins the activity of the $\gamma$-core can differ from the activity of the full length defensin (Sathoff et al., 2019). Alternatively, this may be due to the process used to predict the HoloTickCores which was based on the alignment of the holosins with the $\gamma$-cores that have been identified in the I. ricinus and $I$. scapularis defensins. As shown in Table 1, this strategy resulted in $\gamma$ cores spanning from Cys4 to the C-terminus of the molecules which included only the c-loop. Other $\gamma$-core predictions included the c-loop, but also one fragment of the m-loop (Fig. 3b, (Nigro et al., 2015)). This raises the question of whether the $\gamma$-core of holosins is more similar to human $\beta$-defensins (Nigro et al., 2015) than the $\gamma$-cores of other tick defensins. Further experiments should compare the antimicrobial activity of the $\gamma$-cores shown in Fig. $3 \mathrm{~b}$ and those in Table 1. 

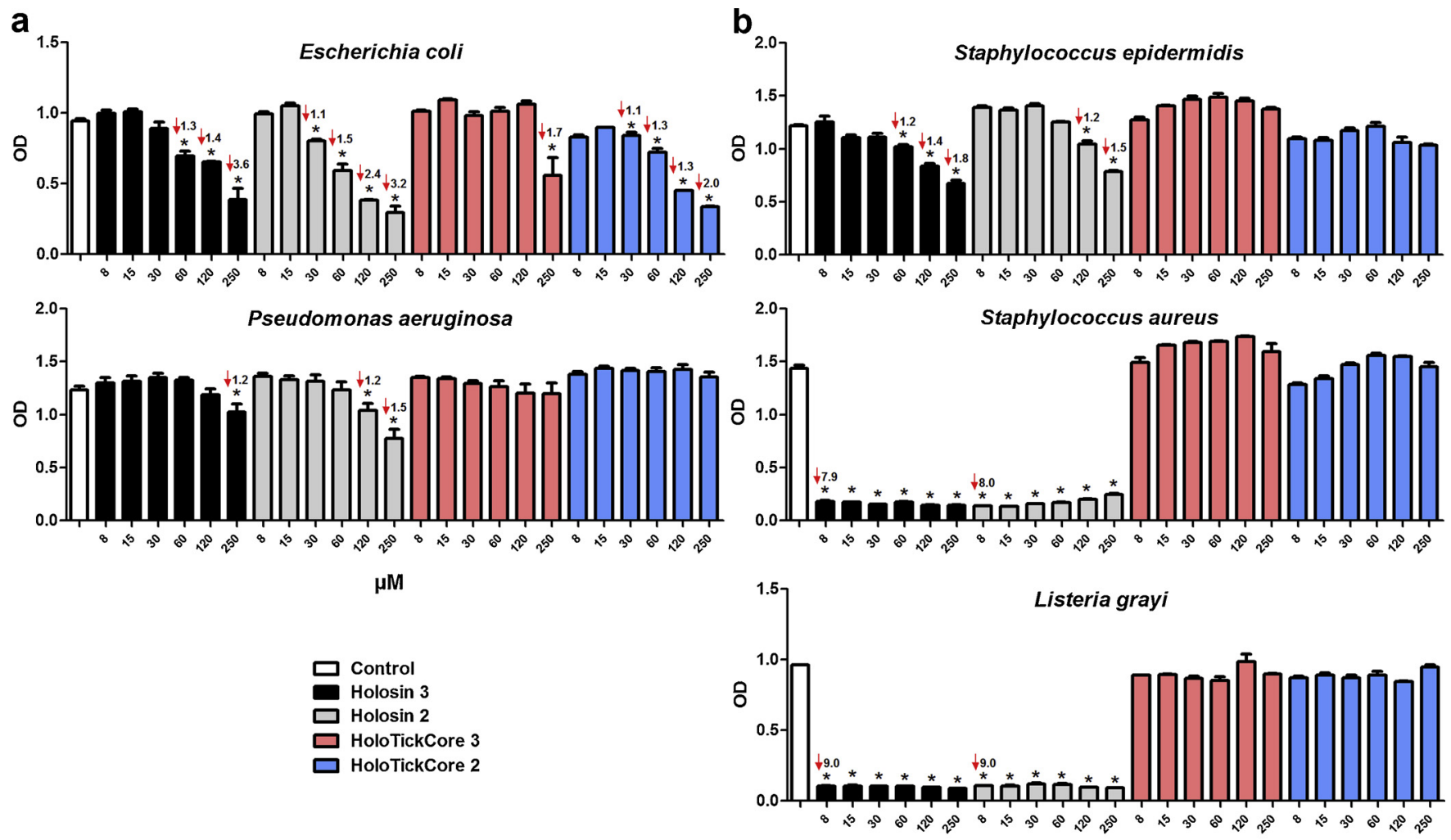

$\mu \mathrm{M}$

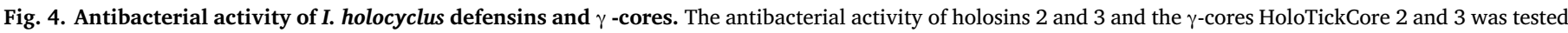

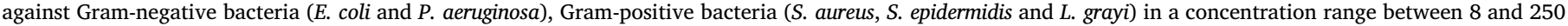

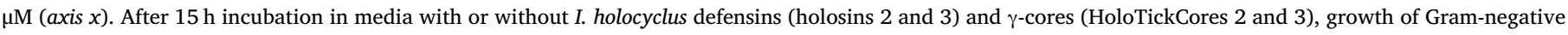

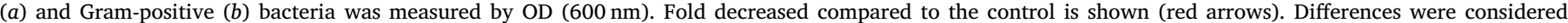

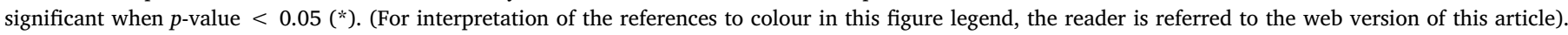

It is generally assumed that the antimicrobial activity of defensins is mediated by peptide-lipid interactions that result in the formation of membrane penetrating pores that destroy the targeted cell (Wimley, 2010; Bechinger and Gorr, 2017). Intriguinly, the activity of tick defensins (i.e. I. holocyclus (this study) and I. ricinus (Tonk et al., 2015b)) against closely related pathogens, e.g. $S$. aureus and $S$. epidermidis, is very different. While low concentrations of holosins $2(2 \mu \mathrm{M})$ and 3 $(0.125 \mu \mathrm{M})$ and DefMT6 $(2 \mu \mathrm{M})$ almost abrogate the growth of $S$. aureus, very high concentration $(250 \mu \mathrm{M})$ of these defensins was necessary to have little or no effect on the growth of $S$. epidermidis. In contrast,
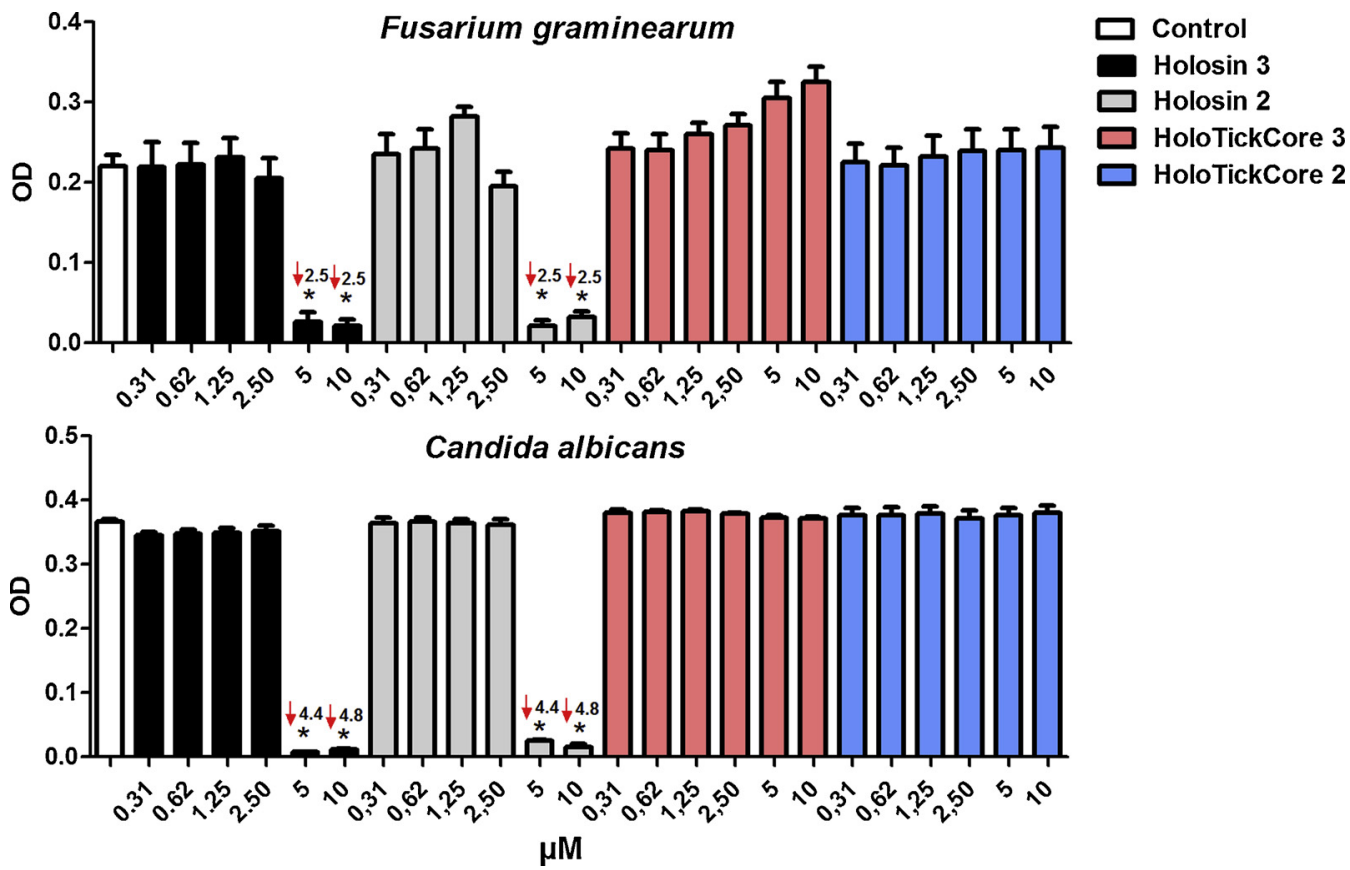

Fig. 5. Antifungal activity of $I$. holocyclus defensins and $\gamma$-cores. Incubation of $F$. graminearum and $C$. albicans was performed in media with or without I. holocyclus defensins (holosins 2 and 3 ) and $\gamma$-cores (HoloTickCores 2 and 3 ) in a concentration range between 0.31 and $10 \mu \mathrm{M}$ (axis $x$ ). The growth was measured by changes in OD $(595 \mathrm{~nm})$ after incubation during $48 \mathrm{~h}$ at $25^{\circ} \mathrm{C}$ for the fungus and $24 \mathrm{~h}$ at $30^{\circ} \mathrm{C}$ for yeast. Fold decreased compared to the control is shown (red arrows). Differences were considered significant when $p$ value $<0.05(*)$. (For interpretation of the references to colour in this figure legend, the reader is referred to the web version of this article). 
Tribolium castaneum defensins Def1 and Def2 were active against $S$. epidermidis at very low concentration while they had no activity on the growth of $S$. aureus at the highest concentration tested $250 \mu \mathrm{M}$ (Tonk et al., 2015b). In our study, the characterization of the antimicrobial effects of holosins was limited to the quantification of microbial growth by measuring variations in OD in treated versus untreated microoganisms over time. Other methods such as counting colony forming units using agar plates, scanning microscopy and lipid binding assays can complement OD analysis towards a better understanding of the antimicrobial effect of tick defensins. The combination of these methods with structure-function analysis could elucidate the mechanism of action of tick and insect defensins and this knowledge could be used to develop novel antimicrobial drugs.

The current increase in bacterial and fungal pathogens that are resistant to antibiotics and antifungal drugs, respectively, is of major concern in this post-antibiotic era (Davies and Davies, 2010; Bush et al., 2011; Coates et al., 2011; CDC, 2013; Li and Webster, 2018). Consequently, the broad antimicrobial property of tick defensins has potential applications in plant, human and animal health for the control of antibiotic resistant pathogens. In addition, the gradual increase in tickborne diseases in recent years together with the absence of effective vaccines posed a serious challenge to human and animal health (Mansfield et al., 2017). All these elements highlight the importance of our study which has enhanced our knowledge of the tick defensin family from I. holocyclus, and the microbiological and biotechnological applications of these defensins.

\section{Conclusion}

In this study five defensins from I. holocyclus, named holosins 1-5, have been annotated, classified into the CS- $\alpha \beta$ defensin family and their biological activity studied. Selected holosins 2 and 3 inhibit the growth of Gram-positive and Gram-negative bacteria and fungi. Tested holosins were highly effective against $S$. aureus but had only a minor activity on the closely related bacteria $S$. epidermidis. High-resolution crystal structures of defensins combined with antimicrobial effect assays may assist the elucidation of the mechanism of action of tick defensins. This knowledge can be used to develop novel antimicrobial compounds against bacteria and fungi that are resistant to existing antibiotic and antifungal drugs.

\section{Acknowledgements}

JJV is supported by Project FIT (Pharmacology, Immunotherapy, nanoToxicology), which was funded by the European Regional Development Fund and acknowledges a grant from the research organization RVO: RO0516. Transcriptome analysis of I. holocyclus viscera and salivary glands was funded by the Australian Research Council linkage project LP120200836 and Elanco Animal Health. MT and AV would like to acknowledge generous funding by the Hessen State Ministry of Higher Education, Research and the Arts (HMWK) via the LOEWE Centre for Translational Biodiversity Genomics (LOEWE-TBG) and the LOEWE Center for Insect Biotechnology and Bioresources.

\section{Appendix A. Supplementary data}

Supplementary material related to this article can be found, in the online version, at doi:https://doi.org/10.1016/j.ttbdis.2019.101269.

\section{References}

Almagro Armenteros, J.J., Sonderby, C.K., Sonderby, S.K., Nielsen, H., Winther, O., 2017. DeepLoc: prediction of protein subcellular localization using deep learning. Bioinformatics. 33, 3387-3395.

Altschul, S.F., Gish, W., Miller, W., Myers, E.W., Lipman, D.J., 1990. Basic local alignment search tool. J. Mol. Biol. 215, 403-410.

Anatriello, E., Ribeiro, J.M., De Miranda-Santos, I.K., Brandao, L.G., Anderson, J.M.,
Valenzuela, J.G., Maruyama, S.R., Silva, J.S., Ferreira, B.R., 2010. An insight into the sialotranscriptome of the brown dog tick, Rhipicephalus sanguineus. BMC Genomics $11,450$.

Bechinger, B., Gorr, S.U., 2017. Antimicrobial peptides: mechanisms of action and resistance. J. Dent. Res. 96, 254-260.

Berman, H.M., Westbrook, J., Feng, Z., Gilliland, G., Bhat, T.N., Weissig, H., Shindyalov, I.N., Bourne, P.E., 2000. The protein data bank. Nucleic Acids Res. 28, 235-242.

Borrelli, K.W., Vitalis, A., Alcantara, R., Guallar, V., 2005. PELE: protein energy landscape exploration. A novel Monte Carlo based technique. J. Chem. Theory Comput. 1, 1304-1311.

Broekaert, W.F., Terras, F.R.G., Cammue, B.P.A., Vanderleyden, J., 1990. An automated quantitative assay for fungal growth inhibition. FEMS Microbiol. Lett. 69, 55-59.

Bulet, P., Hetru, C., Dimarcq, J.-L., Hoffmann, D., 1999. Antimicrobial peptides in insects; structure and function. Dev. Comp. Immunol. 23, 329-344.

Bush, K., Courvalin, P., Dantas, G., Davies, J., Eisenstein, B., Huovinen, P., Jacoby, G.A., Kishony, R., Kreiswirth, B.N., Kutter, E., Lerner, S.A., Levy, S., Lewis, K., Lomovskaya, O., Miller, J.H., Mobashery, S., Piddock, L.J., Projan, S., Thomas, C.M., Tomasz, A., Tulkens, P.M., Walsh, T.R., Watson, J.D., Witkowski, J., Witte, W., Wright, G., Yeh, P., Zgurskaya, H.I., 2011. Tackling antibiotic resistance. Nat. Rev. Microbiol. 9, 894-896.

Cabezas-Cruz, A., Tonk, M., Bouchut, A., Pierrot, C., Pierce, R.J., Kotsyfakis, M., Rahnamaeian, M., Vilcinskas, A., Khalife, J., Valdés, J.J., 2016. Antiplasmodial activity is an ancient and conserved feature of tick defensins. Front. Microbiol. 7, 1682.

CDC, 2013. Antibiotic Resistance Threats in the United Stated Report 2013. C.F.D.C.a.P. U.S. Department of Health and human services.

Ceraul, S.M., Sonenshine, D.E., Ratzlaff, R.E., Hynes, W.L., 2003. An arthropod defensin expressed by the hemocytes of the American dog tick, Dermacentor variabilis (Acari: ixodidae). Insect Biochem. Mol. Biol. 33, 1099-1103.

Chrudimska, T., Chrudimsky, T., Golovchenko, M., Rudenko, N., Grubhoffer, L., 2010. New defensins from hard and soft ticks: similarities, differences, and phylogenetic analyses. Vet. Parasitol. 167, 298-303.

Chrudimská, T., Slaninova, J., Rudenko, N., Ruzek, D., Grubhoffer, L., 2011. Functional characterization of two defensin isoforms of the hard tick Ixodes ricinus. Parasit. Vectors 4, 63.

Coates, A.R., Halls, G., Hu, Y., 2011. Novel classes of antibiotics or more of the same? Br. J. Pharmacol. 163, 184-194.

Couto, J., Tonk, M., Ferrolho, J., Antunes, S., Vilcinskas, A., de La Fuente, J., Domingos, A., Cabezas-Cruz, A., 2018. Antiplasmodial activity of tick defensins in a mouse model of malaria. Ticks Tick. Dis. 9, 844-849.

Crooks, G.E., Hon, G., Chandonia, J.-M., Brenner, S.E., 2004. WebLogo: a sequence logo generator. Genome Res. 14, 1188-1190.

Davies, J., Davies, D., 2010. Origins and evolution of antibiotic resistance. Microbiol. Mol. Biol. Rev. 74, 417-433.

Enright, A.J., Van Dongen, S., Ouzounis, C.A., 2002. An efficient algorithm for large-scale detection of protein families. Nucleic Acids Res. 30, 1575-1584.

Fogaça, A.C., Lorenzini, D.M., Kaku, L.M., Esteves, E., Bulet, P., Daffre, S., 2004. Cysteinerich antimicrobial peptides of the cattle tick Boophilus microplus: isolation, structural characterization and tissue expression profile. Dev. Comp. Immunol. 28, 191-200.

Goonesekere, N.C., Lee, B., 2008. Context-specific amino acid substitution matrices and their use in the detection of protein homologs. Proteins. 71, 910-919.

Graves, S.R., Stenos, J., 2017. Tick-borne infectious diseases in Australia. Med. J. Aust. 206, 320-324.

Hajdusek, O., Sima, R., Ayllón, N., Jalovecká, M., Perner, J., de La Fuente, J., Kopáček, P., 2013. Interaction of the tick immune system with transmitted pathogens. Front. Cell. Infect. Microbiol. 3, 26.

Holm, L., Laakso, L.M., 2016. Dali server update. Nucleic Acids Res. 44, W351-5.

Humphrey, W., Dalke, A., Schulten, K., 1996. VMD: visual molecular dynamics. J. Mol. Graph. 14 (33-8), 27-28.

Jorgensen, W.L., Maxwell, D.S., Tirado-Rives, J., 1996. Development and testing of the OPLS all-atom force field on conformational energetics and properties of organic liquids. J. Am. Chem. Soc. 118, 11225-11236.

Katoh, K., Standley, D.M., 2013. MAFFT multiple sequence alignment software version 7: improvements in performance and usability. Mol. Biol. Evol. 30, 772-780.

Kopáček, P., Hajdušek, O., Burešová, V., Daffre, S., 2010. Tick innate immunity. Invertebrate Immunity. Springer, pp. 137-162.

Krysan, D.J., Rockwell, N.C., Fuller, R.S., 1999. Quantitative characterization of furin specificity. Energetics of substrate discrimination using an internally consistent set of hexapeptidyl methylcoumarinamides. J. Biol. Chem. 274, 23229-23234.

Li, B., Webster, T.J., 2018. Bacteria antibiotic resistance: new challenges and opportunities for implant-associated orthopedic infections. J. Orthop. Res. 36, 22-32.

Liu, L., Dai, J., Zhao, Y.O., Narasimhan, S., Yang, Y., Zhang, L., Fikrig, E., 2012. Ixodes scapularis JAK-STAT pathway regulates tick antimicrobial peptides, thereby controlling the agent of human granulocytic anaplasmosis. J. Infect. Dis. 206, 1233-1241.

Madadkar-Sobhani, A., Guallar, V., 2013. PELE web server: atomistic study of biomolecular systems at your fingertips. Nucleic Acids Res. 41, W322-8.

Mansfield, K.L., Jizhou, L., Phipps, L.P., Johnson, N., 2017. Emerging tick-borne viruses in the twenty-first century. Front. Cell. Infect. Microbiol. 7, 298.

Marchler-Bauer, A., Lu, S., Anderson, J.B., Chitsaz, F., Derbyshire, M.K., Deweese-Scott, C., Fong, J.H., Geer, L.Y., Geer, R.C., Gonzales, N.R., Gwadz, M., Hurwitz, D.I., Jackson, J.D., Ke, Z., Lanczycki, C.J., Lu, F., Marchler, G.H., Mullokandov, M., Omelchenko, M.V., Robertson, C.L., Song, J.S., Thanki, N., Yamashita, R.A., Zhang, D., Zhang, N., Zheng, C., Bryant, S.H., 2010. CDD: a Conserved Domain Database for the functional annotation of proteins. Nucleic Acids Res. 39, D225-D229.

Nakajima, Y., Van Der Goes Van, Naters-Yasui, A., Taylor, D., Yamakawa, M., 2002 Antibacterial peptide defensin is involved in midgut immunity of the soft tick, 
Ornithodoros moubata. Insect Mol. Biol. 11, 611-618.

Nakajima, Y., Ishibashi, J., Yukuhiro, F., Asaoka, A., Taylor, D., Yamakawa, M., 2003. Antibacterial activity and mechanism of action of tick defensin against Gram-positive bacteria. Biochim. Biophys. Acta 1624, 125-130.

Nigro, E., Colavita, I., Sarnataro, D., Scudiero, O., Zambrano, G., Granata, V., Daniele, A., Carotenuto, A., Galdiero, S., Folliero, V., Galdiero, M., Urbanowicz, R.A., Ball, J.K., Salvatore, F., Pessi, A., 2015. An ancestral host defence peptide within human betadefensin 3 recapitulates the antibacterial and antiviral activity of the full-length molecule. Sci. Rep. 5, 18450.

O'Brien, C.A., Hall-Mendelin, S., Hobson-Peters, J., Deliyannis, G., Allen, A., Lew-Tabor, A., Rodriguez-Valle, M., Barker, D., Barker, S.C., Hall, R.A., 2018. Discovery of a novel iflavirus sequence in the eastern paralysis tick Ixodes holocyclus. Arch. Virol. $163,2451-2457$.

Oeemig, J.S., Lynggaard, C., Knudsen, D.H., Hansen, F.T., Norgaard, K.D., Schneider, T., Vad, B.S., Sandvang, D.H., Nielsen, L.A., Neve, S., Kristensen, H.H., Sahl, H.G., Otzen, D.E., Wimmer, R., 2012. Eurocin, a new fungal defensin: structure, lipid binding, and its mode of action. J. Biol. Chem. 287, 42361-42372.

Ong, C.T., Rodriguez-Valle, M., Moolhuijzen, P.M., Barrero, R.A., Hunter, A., Szabo, T., Bellgard, M.I., Lew-Tabor, A.E., 2018. Exploring the transcriptomic data of the Australian paralysis tick, ixodes holocyclus. GSTF. J. Vet. Med. Sci. 2.

Parisi, K., Shafee, T.M., Quimbar, P., Van Der Weerden, N.L., Bleackley, M.R., Anderson, M.A., 2018. The evolution, function and mechanisms of action for plant defensins. Semin. Cell Dev. Biol. Elsevier.

Petersen, T.N., Brunak, S., Von Heijne, G., Nielsen, H., 2011. SignalP 4.0: discriminating signal peptides from transmembrane regions. Nat. Methods 8, 785-786.

Ren, L., Lomas, L.O., Jonczy, J., Turner, P.C., 2004. Two novel non-cationic defensin-like antimicrobial peptides from haemolymph of the female tick, Amblyomma hebraeum. Biochem. J. 379, 681-685.

Rodriguez-Valle, M., Moolhuijzen, P., Barrero, R.A., Ong, C.T., Busch, G., Karbanowicz, T., Booth, M., Clark, R., Koehbach, J., Ijaz, H., Broady, K., Agnew, K., Knowles, A.G., Bellgard, M.I., Tabor, A.E., 2018. Transcriptome and toxin family analysis of the paralysis tick, Ixodes holocyclus. Int. J. Parasitol. 48, 71-82.

Sastry, G.M., Adzhigirey, M., Day, T., Annabhimoju, R., Sherman, W., 2013. Protein and ligand preparation: parameters, protocols, and influence on virtual screening enrichments. J. Comput. Aided Mol. Des. 27, 221-234.

Sathoff, A.E., Velivelli, S., Shah, D.M., Samac, D.A., 2019. Plant defensin Peptides have antifungal and antibacterial activity against human and plant pathogens. Phytopathology. 109, 402-408.

Shafee, T.M., Lay, F.T., Phan, T.K., Anderson, M.A., Hulett, M.D., 2017. Convergent evolution of defensin sequence, structure and function. Cell. Mol. Life Sci. 74, 663-682.

Sun, T., Pan, W., Song, Y., Zhang, J., Wang, J., Dai, J., 2017. Functional characterization of two defensins, HIDFS1 and HIDFS2, from the hard tick Haemaphysalis longicornis. Parasit. Vectors 10, 455.

Tamura, K., Stecher, G., Peterson, D., Filipski, A., Kumar, S., 2013. MEGA6: molecular evolutionary genetics analysis version 6.0. Mol. Biol. Evol. 30, 2725-2729.

Tatusov, R.L., Fedorova, N.D., Jackson, J.D., Jacobs, A.R., Kiryutin, B., Koonin, E.V., Krylov, D.M., Mazumder, R., Mekhedov, S.L., Nikolskaya, A.N., Rao, B.S., Smirnov,
S., Sverdlov, A.V., Vasudevan, S., Wolf, Y.I., Yin, J.J., Natale, D.A., 2003. The COG database: an updated version includes eukaryotes. BMC Bioinformatics 4, 41.

Taylor, D., 2006. Innate immunity in ticks: a review. J. Acarol. Soc. Jpn. 15, 109-127.

Todd, S.M., Sonenshine, D.E., Hynes, W.L., 2007. Tissue and life-stage distribution of a defensin gene in the lone star tick, Amblyomma americanum. Med. Vet. Entomol. 21, 141-147.

Tonk, M., Cabezas-Cruz, A., Valdés, J.J., Rego, R.O., Chrudimská, T., Strnad, M., Šíma, R., Bell-Sakyi, L., Franta, Z., Vilcinskas, A., Grubhoffer, L., Rahnamaeian, M., 2014a. Defensins from the tick Ixodes scapularis are effective against phytopathogenic fungi and the human bacterial pathogen Listeria grayi. Parasit. Vectors 7, 554.

Tonk, M., Cabezas-Cruz, A., Valdes, J.J., Rego, R.O., Rudenko, N., Golovchenko, M., BellSakyi, L., de la Fuente, J., Grubhoffer, L., 2014b. Identification and partial characterisation of new members of the Ixodes ricinus defensin family. Gene. 540, $146-152$.

Tonk, M., Cabezas-Cruz, A., Valdés, J.J., Rego, R.O., Grubhoffer, L., Estrada-Pena, A., Vilcinskas, A., Kotsyfakis, M., Rahnamaeian, M., 2015a. Ixodes ricinus defensins attack distantly-related pathogens. Dev. Comp. Immunol. 53, 358-365.

Tonk, M., Knorr, E., Cabezas-Cruz, A., Valdés, J.J., Kollewe, C., Vilcinskas, A., 2015b. Tribolium castaneum defensins are primarily active against gram-positive bacteria. J. Invert. Pathol. 132, 208-215.

Tsuji, N., Battsetseg, B., Boldbaatar, D., Miyoshi, T., Xuan, X., Oliver Jr., J.H., Fujisaki, K., 2007. Babesial vector tick defensin against Babesia sp. parasites. Infect. Immun. 75, 3633-3640.

Valdes, J.J., Schwarz, A., Cabeza De Vaca, I., Calvo, E., Pedra, J.H., Guallar, V., Kotsyfakis, M., 2013. Tryptogalinin is a tick Kunitz serine protease inhibitor with a unique intrinsic disorder. PLoS One 8, e62562.

Von Mering, C., Jensen, L.J., Kuhn, M., Chaffron, S., Doerks, T., Krüger, B., Snel, B., Bork, P., 2006. STRING 7-recent developments in the integration and prediction of protein interactions. Nucleic Acids Res. 35, D358-D362.

Wang, J., Bian, G., Pan, W., Feng, T., Dai, J., 2015. Molecular characterization of a defensin gene from a hard tick, Dermacentor silvarum. Parasit. Vectors 8, 25.

Wang, Y., Zhu, S., 2011. The defensin gene family expansion in the tick ixodes scapularis. Dev. Comp. Immunol. 35, 1128-1134.

Whelan, S., Goldman, N., 2001. A general empirical model of protein evolution derived from multiple protein families using a maximum-likelihood approach. Mol. Biol. Evol. 18, 691-699.

Wimley, W.C., 2010. Describing the mechanism of antimicrobial peptide action with the interfacial activity model. ACS Chem. Biol. 5, 905-917.

Yamaguchi, Y., Ouchi, Y., 2012. Antimicrobial peptide defensin: identification of novel isoforms and the characterization of their physiological roles and their significance in the pathogenesis of diseases. Proc. Jpn. Acad., Ser. B, Phys. Biol. Sci. 88, 152-166.

Yount, N.Y., Yeaman, M.R., 2004. Multidimensional signatures in antimicrobial peptides. Proc. Natl. Acad. Sci. U. S. A. 101, 7363-7368.

Zhang, L.-J., Gallo, R.L., 2016. Antimicrobial peptides. Curr. Biol. 26, R14-R19.

Zhang, Y., 2008. I-TASSER server for protein 3D structure prediction. BMC Bioinformatics $9,40$.

Zhu, S., Gao, B., Harvey, P.J., Craik, D.J., 2012. Dermatophytic defensin with antiinfective potential. Proc. Natl. Acad. Sci. U. S. A. 109, 8495-8500. 